Rapid Reviews COVID-19

\title{
Reviews of "The Effect of Information Behavior in Media on Perceived and Actual Knowledge about the COVID-19 Pandemic"
}

Eric Merkley ${ }^{1}$, Neil Weinstein ${ }^{2}$

1 University of Toronto, Political Science, Canada,

${ }^{2}$ Professor Emeritus, Rutgers University System: Rutgers The State University of New Jersey, Human Ecology, USA

Published on: Dec 02, 2020

DOI: 10.1162/2e3983f5.d3df111b

License: Creative Commons Attribution 4.0 International License (CC-BY 4.0). 
To read the original manuscript, click the link above.

Summary of Reviews: Reviewers find that this manuscript offers some important exploratory findings pertaining to media consumption and perceived knowledge of COVID-19, however they raise significant methodological concerns with interpreting the causality of these findings.

\section{Reviewer 1 (Eric Merkley) |}

\section{Reviewer 2 (Neil Weinstein) |}

\section{RR:C19 Strength of Evidence Scale Key.}

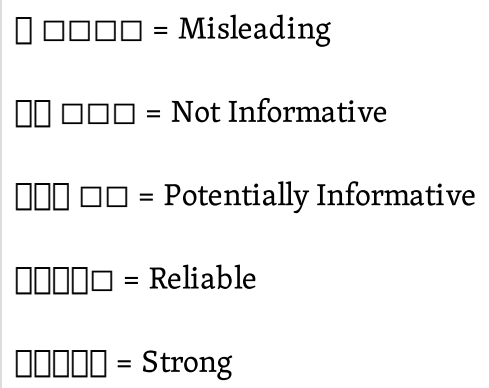

To read the reviews, click the links below. 